\title{
Combining Isoelectric Point-Based Fractionation, Liquid Chromatography and Mass Spectrometry to Improve Peptide Detection and Protein Identification
}

\author{
Stephanie M. Cologna, William K. Russell, Peniel J. Lim, Gyula Vigh, \\ and David H. Russell \\ Department of Chemistry, Texas A and M University, College Station, Texas, USA
}

\begin{abstract}
The off-line coupling of an isoelectric trapping device termed membrane separated wells for isoelectric focusing and trapping (MSWIFT) to mass spectrometry-based proteomic studies is described. The MSWIFT is a high capacity, high-throughput, mass spectrometry-compatible isoelectric trapping device that provides isoelectric point $(\mathrm{pI})$-based separations of complex mixtures of peptides. In MSWIFT, separation and analyte trapping are achieved by migrating the peptide ions through membranes having fixed $\mathrm{pH}$ values until the peptide $\mathrm{pI}$ is bracketed by the $\mathrm{pH}$ values of adjacent membranes. The $\mathrm{pH}$ values of the membranes can be tuned, thus affording a high degree of experimental flexibility. Specific advantages of using MSWIFT for sample prefractionation include: (1) small sample volumes $(\sim 200 \mu \mathrm{L}),(2)$ customized membranes over a large $\mathrm{pH}$ range, (3) flexibility in the number of desired fractions, (4) membrane compatibility with a variety of solvents systems, and (5) resulting fractions do not require sample cleanup before MS analysis. Here, we demonstrate the utility of MSWIFT for mass spectrometry-based detection of peptides in improving dynamic range and the reduction of ion suppression effects for high-throughput separations of tryptic peptides. (J Am Soc Mass Spectrom 2010, 21, 1612-1619) (c) 2010 American Society for Mass Spectrometry
\end{abstract}

S ample prefractionation techniques are widely used to decrease the complexity of proteomic samples before liquid chromatography and tandem mass spectrometry (LC-MS/MS) analysis [1]. The use of isoelectric focusing (IEF) to separate ampholytic compounds such as peptides or proteins based on differences in isoelectric point (pI) $[2,3]$ is becoming increasingly useful for many different types of mass spectrometry (MS)-based proteomics [4-6]. Early MSbased proteomics utilized two-dimensional gel electrophoresis (2D-GE) [7, 8]; however, IEF also can be achieved in gel matrices, capillaries, and multicompartment electrolyzers (MCEs). Although considerable improvements have been made in 2D-GE, [9-11], there are significant problems associated with the technology [12]; specifically, 2D-GE performs poorly for very large and small proteins, hydrophobic proteins, and proteins with extremely acidic or basic $\mathrm{pI}$ values. Furthermore, proteomic studies based on the coupling of gel electrophoresis and mass spectrometry are labor intensive. To circumvent these limitations, alternative IEF methods such as analytical scale MCEs have been developed and combined successfully with MS for

Address reprint requests to Professor D. H. Russell, Department of Chemistry, Texas A and M University, P.O. Box 30012, College Station, TX 77843, USA. E-mail: russell@mail.chem.tamu.edu proteomic applications [6, 13-19]. Prefractionation devices based on solution IEF enhance several key aspects of the analysis, e.g., (1) they increase the dynamic range owing to a partitioning of high and low abundance species across multiple fractions, and (2) increase the sample loading capability because analyte incorporation into a gel matrix is not required. In addition, separations can be performed in a few hours and analytes are captured and retained in the solution phase [20]. On the other hand, a significant limitation of solution IEF is the increased sample handling required to remove carrier ampholytes before MS analysis.

An alternative carrier ampholyte-free pI-based separation method called isoelectric trapping (IET) has been described [13, 21, 22]. IET uses buffering membranes to create a step-wise $\mathrm{pH}$ gradient, thereby establishing a series of separation wells bracketed by membranes with well-defined $\mathrm{pH}$ values. In IET, proteins or peptides migrate under the influence of an electric field until the individual components reach a compartment in which the $\mathrm{pH}$ values of the buffering membranes bracket the $\mathrm{pI}$ value of the analyte. To reduce protein precipitation, which can occur near or at the isoelectric point [23], the individual compartments can be buffered using small ampholytic molecules, e.g., amino acids [24]. These buffering molecules do not interfere with MS analysis such as matrix assisted laser desorption/ 
ionization (MALDI) owing to their low molecular weights, which fall below the $\mathrm{m} / \mathrm{z}$ range of interest.

Lim and coworkers developed an IET device termed membrane separated wells for isoelectric focusing and trapping (MSWIFT) [25]. The primary advantages of the MSWIFT device for MS-based proteomics include (1) small volumes wells ( $\sim 200 \mu \mathrm{L})$, (2) tunable membranes that cover a wide $\mathrm{pH}$ range $(\mathrm{pH} 2-12)$, (3) option for a large number of fractions, (4) absence of sample cleanup after IET, and (5) membrane compatibility with both aqueous and organic solvent systems. They demonstrated the utility of MSWIFT for separation and concentration of ampholytes while minimizing the detrimental effects associated with fast electrophoretic techniques, i.e., Joule heating and sample overloading. Preliminary experiments from their work include demonstration of desalting capabilities, enrichment of a minor component from a synthetic mixture, and fractionation of egg white proteins, which has implications for proteomics experiments. For comparison, one of the most highly utilized pI-based separation devices for proteomic studies is the OFFGEL Fractionator (Agilent Technologies, Santa Clara, CA, USA). Much of the work using the OFFGEL device has been centered on peptide separations followed by MS analysis. Samples, including cerebral spinal fluid [26], brain tissue [27], and yeast [28, 29], have been analyzed and quantitative studies incorporating iTRAQ labeling have been reported [30,31]. The OFFGEL is an attractive method for peptide fractionation considering its multiplexing abilities-running several strips simultaneously, small sample volume, and low sample quantity requirements. However, several inherent limitations are associated with the technology such as long separation times, sample cleanup requirements, the need for an insulated cooling system, and a lack in the ability to customize the number of wells or $\mathrm{pH}$ ranges. These restrictions, however, are not associated with using the MSWIFT device. Several proof-of-concept experiments specifically focused on bottom-up proteomics are included here to illustrate the compatibility and advantages of using MSWIFT as a prefractionation device for mass spectrometry-based studies.

\section{Experimental}

Chemicals were obtained from Sigma (St. Louis, MO, USA), unless noted otherwise. HPLC grade acetonitrile was purchased from EMD Chemicals, Inc. (Gibbstown, NJ, USA). Peptide standards from American Peptide Company (Sunnyvale, CA, USA) were used without further purification. All experiments were performed using purified 18 $\mathrm{M} \Omega$ water (Barnstead International, Dubuque, IA, USA).

\section{MSWIFT}

The design and assembly of MSWIFT have been previously described [25,32]. Briefly, the main housing of MSWIFT was built using polycarbonate and equipped with an aluminum heat sink. Poly(vinyl-alcohol)-based buffering membranes with tunable $\mathrm{pH}$ values were synthesized in-house [33-36]. A schematic of the MSWIFT assembly is displayed in Figure 1. Features include the anode and cathode compartments, variable number of separation wells, and buffering membranes (labeled a-e from low to high $\mathrm{pH}$ values in Figure 1). A detailed AutoCAD drawing of the device is provided in the supplementary material section (Figure S1), which can be found in the electronic version of this article, and includes the details related to each component.

\section{IET}

Alumina separation wells were assembled serially and buffering membranes were inserted into silicone pouches in between each well. The wells were filled with $200 \mu \mathrm{L}$ of the peptide sample solution and/or an ampholytic buffer. The anode solution was $3 \mathrm{mM}$ methanesulfonic acid, and the cathode solution was 3 $\mathrm{mM}$ sodium hydroxide. Compartment solutions were $\mathrm{pH}$ biased by ampholytic buffers as previously described [24]. Typical separation times ranged from 45 to $60 \mathrm{~min}$ at $5 \mathrm{~W}$ constant power. Theoretical pI values were calculated using the compute $\mathrm{pI} / \mathrm{MW}$ tool from ExPASy [37].

\section{IET of a Five-Peptide Mixture}

The five peptides, leptin (93-105) (NVIQISNDLENLR, pI 4.4), angiotensin II (DRVYIHPF, pI 6.7), angiotensin I

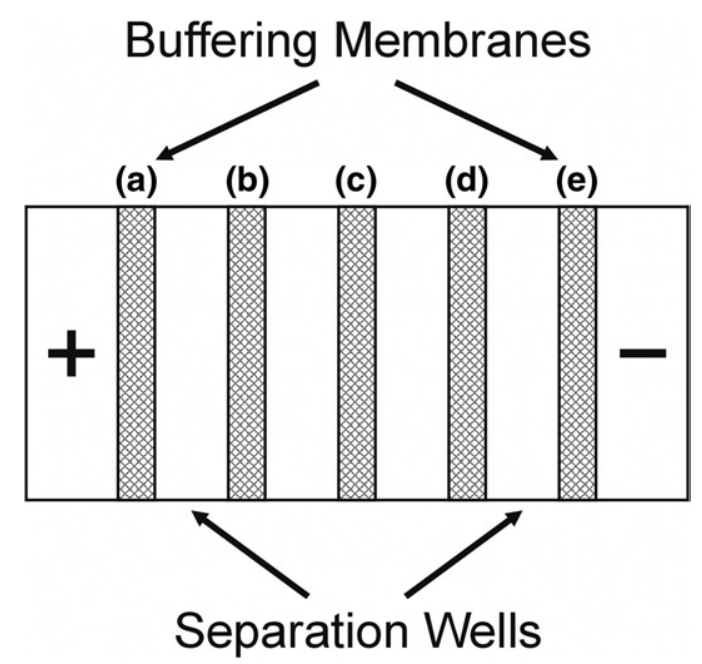

Figure 1. Schematic of MSWIFT assembly including anode/ cathode compartments, separation wells, and buffering membranes. The four compartment setup was used to separate a mixture of five standard peptides followed by MALDI-MS analysis. The $\mathrm{pH}$ values of the buffering membranes used were: 2.9 (a), 5.4 (b), 7.6 (c), 9.0, (d), and 11.0 (e). This configuration would allow for each peptide to be trapped into a single separation well with the exception of angiotensin I and II peptides, which are trapped together in the second separation well. A similar configuration was used in all other experiments, except the number of separation wells and the $\mathrm{pH}$ values of the buffering membranes were tailored to each separation. 
(DRVYIHPFHL, pI 6.9), angiotensin III (RVYIHPF, pI 8.8), and bradykinin fragment 1-7 (RPPGFSP, pI 9.8) were mixed to final concentrations of $0.05 \mathrm{mg} \mathrm{mL}^{-1}$ for leptin and bradykinin and $0.025 \mathrm{mg} \mathrm{mL}^{-1}$ for the angiotensin peptides. The $\mathrm{pH}$ values of the five buffering membranes were 2.9, 5.4, 7.6, 9.0, and 11.0. The peptide mixture was loaded in the fourth separation well bracketed by $\mathrm{pH} 9.0$ and 12.0 membranes then separated. After fractionation, an aliquot from each separation well was analyzed using MALDI-MS.

\section{Proteolytic Digestion and IET of a Five-Protein Mixture}

A protein mixture containing bovine $\alpha$-casein, bovine serum albumin, bovine apo-transferrin, bovine ribonuclease A, and horse cytochrome $c$ (10 $\mu \mathrm{g}$ each) was prepared in $50 \mathrm{mM}$ ammonium bicarbonate buffer, $\mathrm{pH}$ 8 . The protein mixture was reduced by adding dithiothreitol to a final concentration of $5 \mathrm{mM}$ followed by incubation at $60^{\circ} \mathrm{C}$ for $1 \mathrm{~h}$. Alkylation was performed by adding methane methylthiosulfonate (MMTS) (20 $\mathrm{mM}$ final concentration) and the solution was incubated at room temperature for $10 \mathrm{~min}$. Trypsin (Promega Corp., Madison, WI, USA) was added at an enzyme to protein ratio of 1:50 (wt/wt) and digestion was carried out at $37^{\circ} \mathrm{C}$ overnight. The resulting peptides were loaded into the second separation well of MSWIFT (bracketed by $\mathrm{pH}$ 4.5-5.4 membranes) and subjected to IET separation. The $\mathrm{pH}$ values of all the membranes were as follows: 2.0, 4.5, 5.4, 6.5, 7.6, 8.2, and 12.0. Following separation, MALDI-MS analysis was performed using an aliquot obtained from each fraction.

\section{Proteolytic Digestion, IET, and LC-MS/MS Analysis of Yeast Lysate}

Soluble yeast proteins (Saccharomyces cerevisiae) were prepared in $100 \mathrm{mM}$ 3-morpholinopropane sulfonic acid (MOPS), $100 \mathrm{mM}$ sodium chloride, $5 \mathrm{mM}$ ethylenediaminetetraacetic acid (EDTA) with protease inhibitors. Protein concentrations were determined using the Bradford Assay [38]. A total of $180 \mu \mathrm{g}$ of protein was reduced using tris-(2-carboxyethyl) phosphine at a final concentration of $5 \mathrm{mM}$ and incubated at $60{ }^{\circ} \mathrm{C}$ for $1 \mathrm{~h}$. Alkylation using MMTS and trypsin digestion were carried out as outlined for the five-protein mixture. The $\mathrm{pH}$ values of the membranes were as follows: 2.0, 4.7, $5.4,6.5,7.0,8.2$, and 12.0. The sample was loaded in the fourth separation well (bracketed by $\mathrm{pH}$ 6.5-7.0 membranes) and IET was carried out. Following separation, an aliquot from each compartment solution was subjected to reversed-phase liquid chromatography (LC), coupled offline to MALDI-MS/MS analysis via a robotic spotting device as previously described [39]. In the two-stage MSWIFT separation of yeast peptides, an additional $200 \mu \mathrm{g}$ of yeast was digested as above and fractionated. The $\mathrm{pH}$ values of the buffering mem- branes were: $2.9,4.0,5.4,6.8,7.5,9.8$, and 11.0 (first stage) and 4.0, 4.5, 5.0, and 5.4 (second stage). An aliquot of the contents of the $\mathrm{pH} 4.0-5.4$ well in the first stage separation was analyzed using LC-MS/MS then the remaining solution was subjected to further IET fractionation followed by LC-MS/MS analysis.

\section{MALDI-MS and Database Searching}

Samples (excluding yeast) were mixed 1:1 (vol/vol) with the MALDI matrix (5 $\mathrm{mg} \mathrm{mL}^{-1} \alpha$-cyano-4hydroxycinnamic acid, 50\% (vol/vol) acetonitrile, $10 \mathrm{mM}$ ammonium dihydrogen phosphate, $0.1 \%$ trifluoroacetic acid), and $1 \mu \mathrm{L}$ of the resulting mixture was spotted onto a MALDI target. MALDI mass spectra were acquired using either a Voyager DE-STR, Model 4700 or 4800 Proteomics Analyzer (Applied Biosystems, Framingham, MA, USA). Collision-induced dissociation (CID) spectra were acquired using air as the collision gas (medium pressure setting) and at $1 \mathrm{kV}$ of collision energy. Tandem MS data collected for the five-protein mixture and yeast lysate experiments were analyzed using the GPS Explorer Software (Applied Biosystems, Framingham, MA, USA) and an in-house license of the search engine MASCOT (ver. 2.1) [40]. The five-protein mixture data were searched against the Swiss-Prot database with the following search parameters: taxonomy, metazoa; enzyme, trypsin; missed cleavages, 1; variable modifications, oxidation (M), and MMTS (C). Data collected from the yeast separation experiment were searched against the Saccharomyces Genome Database (www.yeastgenome.org, downloaded March 4, 2010, 6717 sequences) with the following parameters: precursor tolerance, $100 \mathrm{ppm}$; fragment ion tolerance, $0.8 \mathrm{Da}$; enzyme: trypsin; missed cleavages, 1; and variable modifications, oxidation (M), and MMTS (C). Protein assignments were made using a minimum of two peptides and a score of $21(P<0.05)$ determined by MASCOT. For reference, we have provided a table of the top 989 protein assignments $(99.990 \%$ confidence interval, two peptide minimum), which includes the 593 identifications obtained from the MASCOT search (Table S3). The same criteria were used for protein identifications in the two-stage separation experiment. Data reporting peptide assignments (two-stage experiment) included all matched peptides without implementing an ion score cut-off.

\section{Results and Discussion}

Lim and coworkers previously reported proof-ofconcept analyte fractionation experiments for a variety of different analytes, ranging from small molecules to egg white proteins. Here, we focus on developing applications of MSWIFT-MALDI-MS for protein identification using 'bottom-up' techniques. For example, MSWIFT provides an ideal option for peptide-based fractionation followed by MS, MS/MS, and/or reversed-phase LCMS/MS analysis owing to the flexibility in arrangement 
and operation of the device. Oftentimes, the analysis of minor components or even major components that do not ionize well by MALDI or ESI in complex mixtures is severely limited, and a rapid, reproducible fractionation technique can be used to circumvent such problems. Several proof-of-concept experiments specifically focused on bottom-up proteomics are included to illustrate the compatibility and advantages of using MSWIFT as a pre-fractionation device.

Fractionating a mixture of peptides having very different $\mathrm{pI}$ values illustrates the basic operation of the device. A mixture composed of five standard peptides, leptin (pI 4.4), angiotensin II (pI 6.7), angiotensin I (pI 6.9), angiotensin III (pI 8.8), and bradykinin 1-7 (pI 9.8) was analyzed using MALDI-MS before and after fractionation (Figure 2). Note, however, that a signal for the $[\mathrm{M}+\mathrm{H}]^{+}$ion of leptin $(\mathrm{m} / \mathrm{z}$ 1527.81) is not observed in the MALDI spectrum of the mixture (Figure 2a), possibly owing to analyte suppression effects [41]. This same peptide mixture was then fractionated using MSWIFT under conditions where individual peptides should be trapped in wells in which buffering membranes bracket
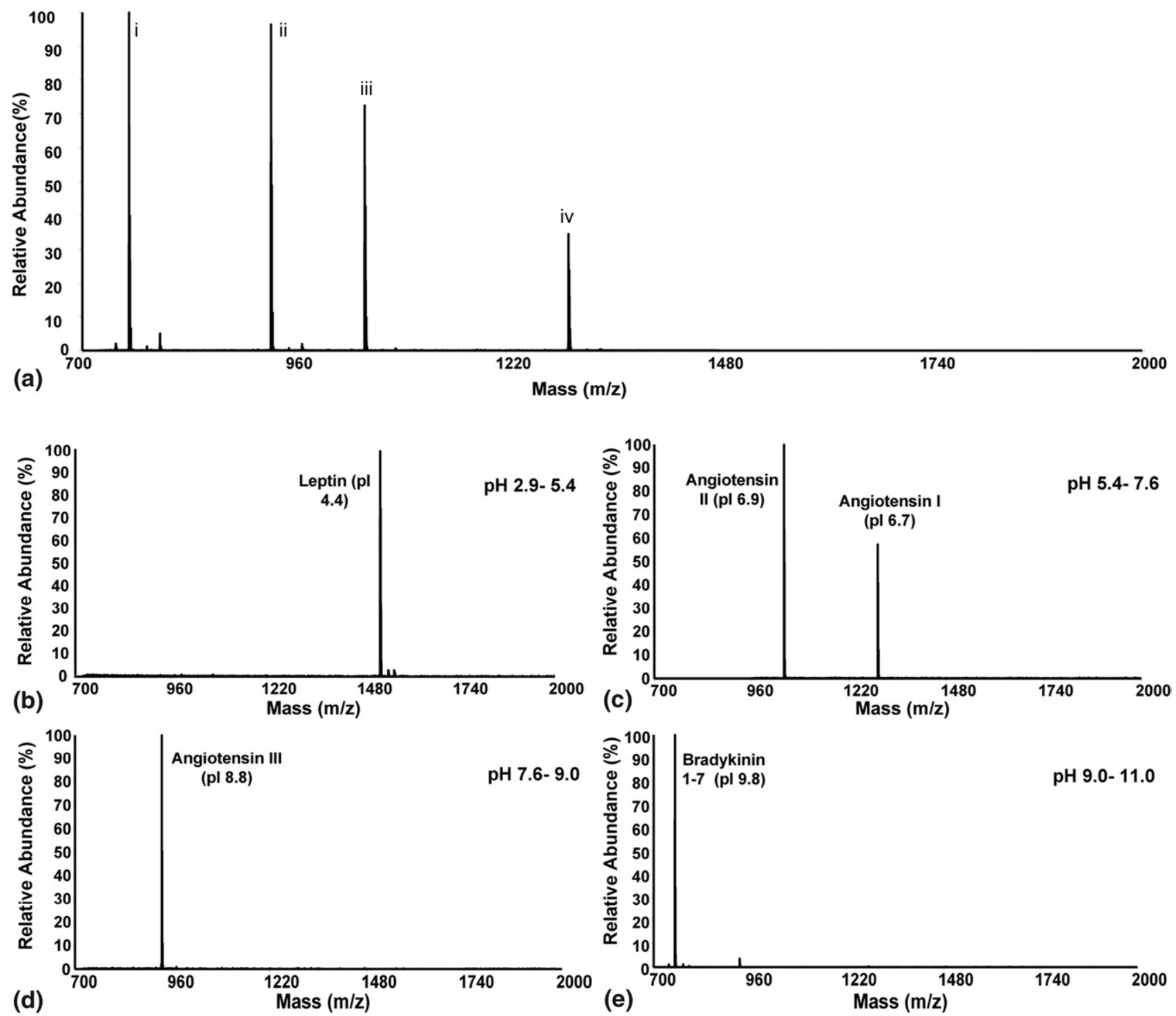

Figure 2. MALDI mass spectrum of a mixture of five peptides before and after IET separation. (a) MALDI mass spectrum of the peptide mixture before separation using the MSWIFT device. The mixture contains (i) bradykinin 1-7 (pI 9.8, $\left.[\mathrm{M}+\mathrm{H}]_{\mathrm{obs}}^{+}=757.39 \mathrm{Da}\right)$, (ii) Angiotensin III (pI 8.8, $\left.[\mathrm{M}+\mathrm{H}]_{\mathrm{obs}}^{+}=931.54 \mathrm{Da}\right)$, (iii) angiotensin I (pI 6.9, $\left.[\mathrm{M}+\mathrm{H}]_{\mathrm{obs}}^{+}=1296.75 \mathrm{Da}\right),(\mathrm{iv})$ Angiotensin II (pI 6.7, $\left.[\mathrm{M}+\mathrm{H}]_{\mathrm{obs}}^{+}=1046.58 \mathrm{Da}\right)$. Each ion signal is labeled with the appropriate peptide with the exception of leptin (pI 4.4, $[\mathrm{M}+\mathrm{H}]_{\text {calc }}^{+}=1527.81 \mathrm{Da}$ ) which is not observed. (b)-(e) MALDI mass spectra taken from an aliquot of each separation well following IET using MSWIFT. The $\mathrm{pH}$ values of the buffering membranes used are indicated in each spectrum. Peptide ion signals are labeled as follows: bradykinin 1-7 (pI 9.8, $\left.[\mathrm{M}+\mathrm{H}]_{\mathrm{obs}}^{+}=757.50 \mathrm{Da}\right)$, angiotensin III $\left(\mathrm{pI} 8.8,[\mathrm{M}+\mathrm{H}]_{\mathrm{obs}}^{+}=931.66 \mathrm{Da}\right)$, angiotensin I $(\mathrm{pI}$ $\left.6.9,[\mathrm{M}+\mathrm{H}]_{\mathrm{obs}}^{+}=1296.88 \mathrm{Da}\right)$, angiotensin II (pI 6.7, $\left.[\mathrm{M}+\mathrm{H}]_{\mathrm{obs}}^{+}=1046.68 \mathrm{Da}\right)$, leptin (pI 4.4, $[\mathrm{M}+$ $\left.\mathrm{H}]_{\mathrm{obs}}^{+}=1527.99 \mathrm{Da}\right)$. 
the $\mathrm{pI}$ value of each peptide (see Figure 1). The $\mathrm{pI}$ values for angiotensin II and angiotensin I peptides are similar (6.7 and 6.9, respectively) and, thus, these two peptides should be trapped in the same compartment. Following fractionation, an aliquot from each fraction was analyzed by MALDI-MS. Figure 2b-e contain the MALDI mass spectra for each of the wells, which are defined by $\mathrm{pH}$ buffering membranes: $\mathrm{pH}$ 2.9-5.4 (2b), $\mathrm{pH} 5.4-7.6$ (2c), pH 7.6-9.0 (2d), and pH 9.0-12.0 (2e). Each of the standard peptides is observed in the predicted well based on the calculated pI values of the peptides and the $\mathrm{pH}$ values of the buffering membranes used. In Figure 2e ( $\mathrm{pH} 9.0-12.0)$, a low abundance signal $(<5 \%$ relative abundance to the bradykinin signal) at $\mathrm{m} / \mathrm{z}$ 931.68 is also observed and corresponds to the [M + $\mathrm{H}]^{+}$ion of angiotensin III (pI 8.8), which may indicate a slightly insufficient electrophoresis time. On the basis of these experiments, we conclude that the MSWIFT device is capable of separating ampholytic components (i.e., peptides) where the resulting fractions can be analyzed using MALDI-MS. Peptides are trapped according to their $\mathrm{pI}$ values, and experimental results agree with theoretical pI calculations. Additional signals, (i.e., leptin) are observed following fractionation highlighting an advantage to using this device and technique.

\section{IET-MS of Complex Mixtures}

Separation of a five-protein tryptic digest. To demonstrate MSWIFT separation/IET of more complex samples, a solution obtained by the proteolytic digestion of a mixture of five proteins: $\alpha$-casein, albumin, apotransferrin, ribonuclease $\mathrm{A}$, and cytochrome $c$ was analyzed. In silico digestion of this five-protein mixture yields a mixture of 345 possible peptides with molecular weights ranging from 500 to $4500 \mathrm{Da}$, assuming a single missed-cleavage. The MALDI mass spectra obtained from an aliquot of each fraction following the IET separation is shown in Figure 3a-f. Inspection of the six resulting mass spectra display varying ion signal patterns, which indicates that the peptides present in each separation well differ from each other. Note that numerous ion signals that are observed following IET are not observed in the nonfractionated samples, and are denoted with filled circles. The peptides observed from the five-protein mixture digest generally have theoretical $\mathrm{pI}$ values that fall within the $\mathrm{pH}$ values of the buffering membranes used in their respective separation wells, which verifies that MSWIFT is trapping the ampholytic components as it should. For example, the signal at $\mathrm{m} / \mathrm{z} 1871.95$ in the well bracketed by $\mathrm{pH}$ 4.5 and 5.4 buffering membranes (Figure $3 \mathrm{~b}$ ) corresponds to the theoretical $\mathrm{m} / \mathrm{z}$ of the $\alpha_{\mathrm{s} 1}$-casein peptide at residues 119-134 (YKVPQLEIVPNSAEER, pI 4.8). A MASCOT database search performed on the six post-fractionation spectra results in the identification of four out of five proteins at the $>99.990 \%$ confidence interval. Ribonuclease A, which is not identified from

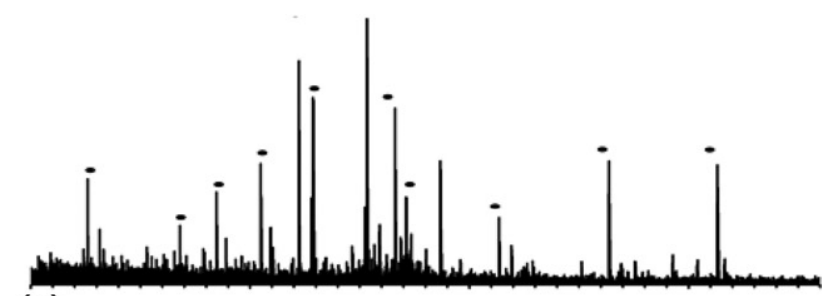

(a)
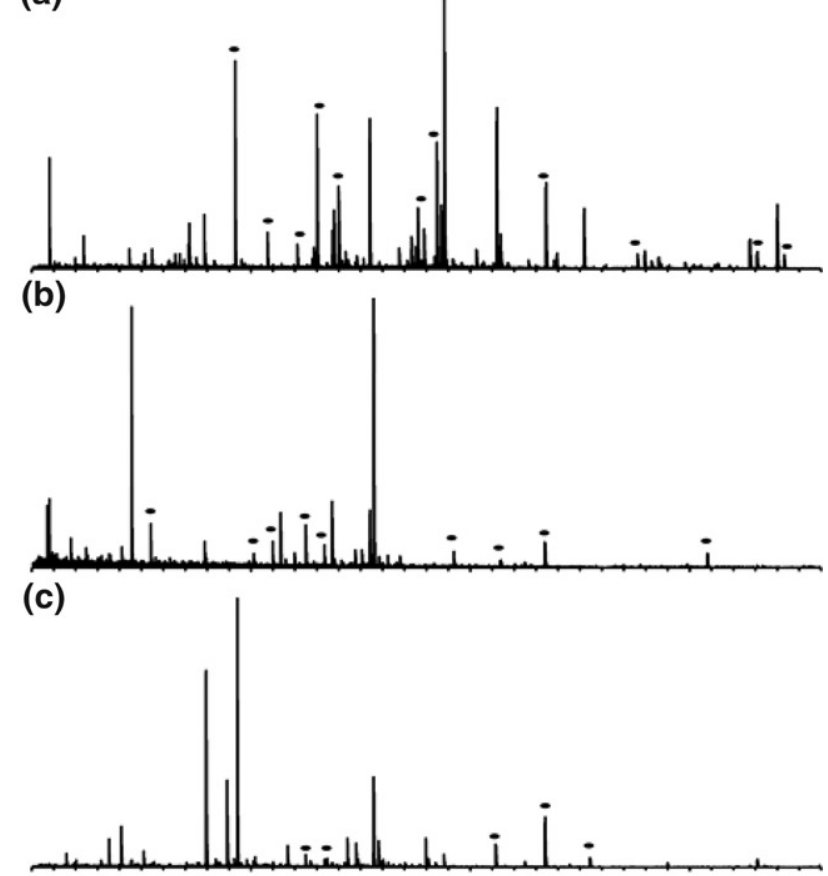

(d)

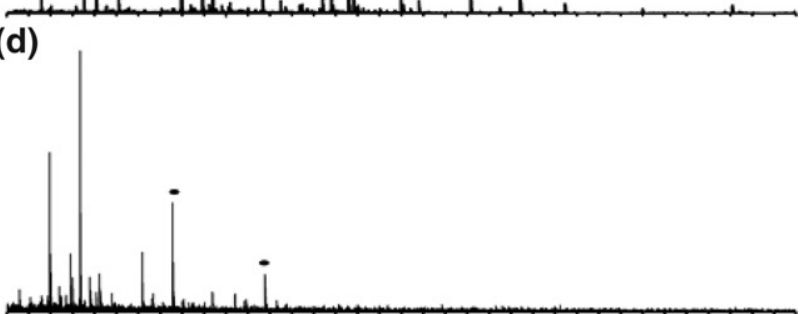

(e)

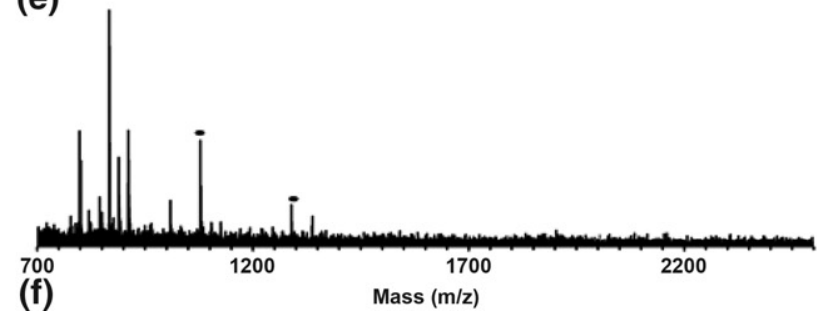

Figure 3. (a)-(f): MALDI mass spectrum of the contents of each MSWIFT separation well from the IET separation of the five protein digestion mixture. The mixture includes tryptic peptides from the proteins bovine serum albumin, apo-transferrin, ribonuclease $\mathrm{A}, \alpha_{\mathrm{s} 1}$-casein, and cytochrome $c$. The $\mathrm{pH}$ values of the buffering membranes used were as follows: (1) $\mathrm{pH} 2.0-4.5$, (2) $\mathrm{pH}$ 4.5-5.4, (3) pH 5.4-6.5, (4) pH 6.5-7.6, (5) pH 7.6-8.2, and (6) $\mathrm{pH}$ 8.2-12.0. Peptide ion signals denoted with a filled circle are those that are not observed in the mass spectrum acquired before IET separation.

database searching, has very few tryptic cleavage sites (13 R or $\mathrm{K}$ residues) and, thus, a limited number of tryptic peptides are observed. Low abundance ion 
signals corresponding to ribonuclease A peptides are observed but were not selected for fragmentation by the automated software. By manual inspection of the mass spectrum obtained from the well bracketed by $\mathrm{pH} 6.5$ and 7.6 membranes, the signals observed at $\mathrm{m} / \mathrm{z} 2353.87$ and 2495.12 can be assigned to tryptic ribonuclease A fragments 37-57 (QHMDSSTSAASSSNYCNQMMK, $[\mathrm{M}+\mathrm{H}]_{\text {calc }}^{+}-2353.91 \mathrm{Da}$ ) and 66-87 (CKPVNTFVHESLADVQAVCSQK, $\left.[\mathrm{M}+\mathrm{H}]_{\text {calc }}^{+}-2495.18 \mathrm{Da}\right)$, respectively. The theoretical $\mathrm{pI}$ value calculated for both of these peptides is 6.7, which falls between the $\mathrm{pH}$ values of the buffering membranes. Therefore, the protein can be assigned with increased confidence based on accurate mass and peptide pI [42].

The amino acid sequence coverage values obtained for the four proteins identified by database searching using only tandem MS data acquired after MSWIFT fractionation are as follows: albumin, 20\%; apo-

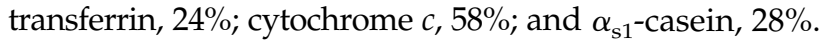
The amino acid sequence coverage of these proteins may be low owing to the limited number of tandem MS spectra acquired for each MALDI spot based on software settings and before sample consumption. For comparison, MS/MS analysis of a tryptic digest of the five-protein mixture without fractionation results in the following sequence coverage values: albumin, $18 \%$; apo-transferrin, $13 \%$; cytochrome $c, 26 \%$; and $\alpha_{\mathrm{s} 1}$-casein, $26 \%$. Most notable are the increases for cytochrome $c$ (32\%) and apo-transferrin (11\%) observed with fractionation. A more significant increase in amino acid sequence coverage would be observed given additional IET experiments or analyzing each fraction using LCMS/MS. However, the goal of this work does not encompass maximizing the coverage for a standard mixture. Note that the majority of peptide ion signals are observed from fractions taken from the first three separation wells ( $\mathrm{pI}$ values $2.0-7.6$ ) and very few signals are observed in the most basic wells. This trend observed from the five-protein mixture digest is also observed by plotting the calculated peptide molecular weight versus theoretical $\mathrm{pI}$ for the in silico digestion of bovine serum albumin where $74 \%$ of the tryptic peptides have $\mathrm{pI}$ values less than 7.6 (data not shown). Separating the five-protein digestion mixture illustrates the ability of MSWIFT to provide initial fractionation after which the resulting fractions can be analyzed using MALDI-MS. However, more sophisticated techniques such as LC or additional IET separations are needed for the analysis of more complex mixtures.

Analysis of a yeast protein digest. Successful analysis of complex mixtures typically relies on two separation techniques. When the separation principles of the two techniques are different, they are considered orthogonal, and the resulting separation or peak capacity is maximized. Therefore, fractions obtained from MSWIFT, which have been separated based on pI, can be further separated using techniques such as capillary electrophoresis or LC. To illustrate this, we chose to separate and analyze the tryptic peptides from soluble S. cerevisiae proteins. Tryptic peptides were first subjected to IET separation using MSWIFT, followed by reversed-phase LC-MS/MS analysis of the contents of each MSWIFT separation well. From database searching, 593 proteins were identified from a single analysis with high confidence. Similarly, Yates and coworkers successfully identified yeast proteins by separating peptides using strong cation exchange and reversed-phase LC-MS/MS known as the MudPIT approach [43]. Haynes et al. analyzed yeast proteins using a variety of separation techniques including strong cation exchange and reversed-phase chromatography as well as electrophoretic methods (i.e., SDS-PAGE, IEF) [44]. Analysis of our data indicates that fractionation was successful as observed in Figure 4, where the number of unique protein assignments from each fraction is plotted as well as the total number unique protein identifications in the last column. The breakdown of the number of protein identifications by fraction is: $0(\mathrm{pH} 2.0-4.7), 256$ (pH 4.7-5.4), 116 (pH 5.4-6.5), 305 (pH 6.5-7.0), 257 (pH $7.0-8.2), 153$ (pH 8.2-12.0), and 593 combined. The analysis of proteins with high and low values of $\mathrm{pI}$ or MW is not compromised using the MSWIFT device and LC-MS/MS in a bottom-up approach. For example, Stress Protein DDR48 and 60S Ribosomal Protein L19A were both identified and have calculated pI values of 4.22 and 11.35 , respectively. Furthermore, protein size is not problematic since peptides are being fractionated. For example, the $245 \mathrm{kD}$ protein URA2 and $12 \mathrm{kD}$ heat shock protein were both identified. An additional benefit is the amount of material that was loaded. Compared with gel-based methods, there is no limit to the amount of sample that can be fractionated. Although our experiment utilizes $180 \mu \mathrm{g}$, much larger amounts (i.e., mg scale) could easily be fractionated as was demonstrated in early experiments [25]. Furthermore, using this experimental scheme allows incorporation of $\mathrm{pI}$ for low scoring peptides to improve confidence in assignment. Take, for example, the peptide, ${ }^{85}$ IDSVIHFAGLK $^{95}$ from the protein UDP-

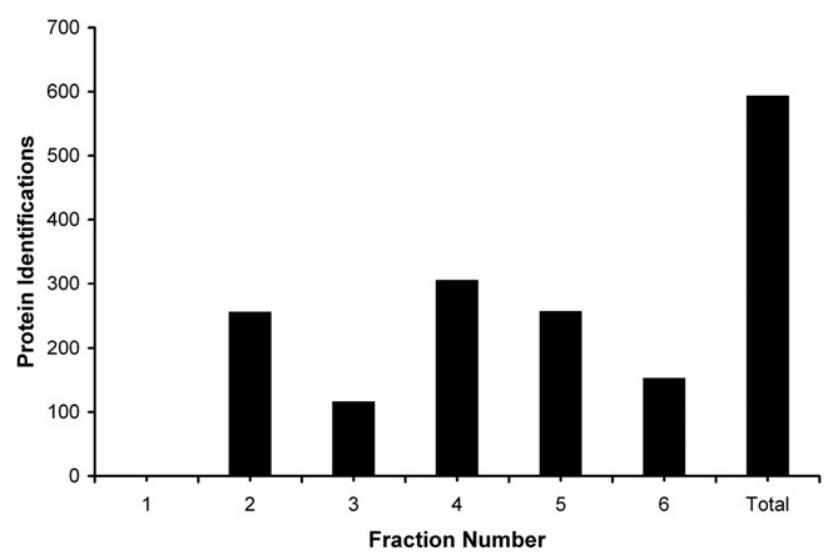

Figure 4. Plot of the number of unique proteins identified in each fraction of the MSWIFT. The final column represents the total number of proteins identified by database searching tandem MS data obtained from all six fractions. 
glucose-4-epimerase (GAL10). Based on tandem MS data and a MASCOT score of 15 , peptide assignment may not be regarded as highly confident. However, considering that the peptide has a theoretical pI value of 6.7 and is observed in the $\mathrm{pH}$ 6.5-7.0 well increases the confidence in the peptide assignment [45]. Utilizing pI to improve peptide assignment may not always be feasible because the theoretical pI value is for an aqueous environment assuming that all residues are exposed and does not account for peptide or protein structure. Nevertheless, in cases such as the above example, pI clearly assists in the peptide assignment.

Another feature of the MSWIFT device is the ability to fractionate a sample multiple times. To demonstrate the utility of multi-stage separation experiments, we fractionated tryptic peptides from yeast into six fractions. Based on manual inspection of the MALDI mass spectrum taken of each fraction, the second well $\mathrm{kH}$ 4.0-5.4) looked the most complex; this assumption is supported by earlier studies for Escherichia coli tryptic peptides [46]. Following initial fractionation, an aliquot of the contents of the $\mathrm{pH} 4.0-5.4$ well was analyzed using LC-MS/MS and the remaining solution was then fractionated a second time using MSWIFT into three additional wells ( $\mathrm{pH} 4.0-4.5, \mathrm{pH} 4.5-5.0$, and $\mathrm{pH} 5.0-$ 5.4). The contents of the three wells from the second stage were also analyzed using LC-MS/MS. Preliminary data from this experiment results in 696 peptides identified corresponding to 155 protein identifications from the first dimension of separation. Following a second stage of fractionation, the combined LC-MS/MS data resulted in an approximate 2-fold increase in the number of identified peptides to 1436 corresponding to 231 protein identifications. The LC-MS/MS data obtained from each of the three wells in the second stage of fractionation was also subjected to database searching and the number of peptides and protein assignments are provided in Table S2. The greatest number of peptide and protein identifications (813 peptides and 203 proteins) from the second stage separation was observed in the $\mathrm{pH}$ 4.5-5.0 fraction. Manual inspection of the preliminary data suggests that the majority of peptides are observed in their proper well and very few peptides are being assigned in multiple wells which serve an additional indicator that MSWIFT works as an efficient pI-based separation device. Utilizing a multistage separation scheme increases the ability to identify low abundance proteins in the presence of highly abundant proteins. An example from these data is the identified proteins proteinase B that is present at 1600 copies per cell and pyruvate kinase, which is present at 291,000 copies per cell (www.yeastgenome.org). These results suggest that to identify low abundance proteins and peptides, fractionation is essential and the ability to perform several dimensions of fractionation followed by LC-MS/MS analysis greatly increases the number of peptides that can be identified. In turn, the number of protein identifications will increase as well as the confidence in protein assignment.

\section{Conclusions}

The utility of MSWIFT for fractionation of peptides on the basis of $\mathrm{pI}$ followed by MALDI-MS and LC-MS/MS analysis is demonstrated for both model peptide mixtures and for the analysis of a complex proteome (yeast lysate). Amino acid sequence coverage values obtained for peptide mass mapping and tandem MS are typically higher following fractionation compared with direct analysis of the mixture. For example, numerous peptide ion signals, which are not observed in crude mixtures, are observed following MSWIFT fractionation. We have successfully used MSWIFT for a large scale proteomic analysis by separating tryptic peptides from yeast followed by LC-MS/MS and demonstrated that several hundred proteins can be assigned from a single analysis, and that the number of peptide identifications is distributed throughout the MSWIFT fractions. Peptides with low MASCOT scores can be assigned with increased confidence when theoretical pI values fall between the $\mathrm{pH}$ values of the buffering membranes. Finally, we have performed initial experiments showing the ability to carry out multiple separations on a single sample by taking a first stage fraction and further fractionating the contents. By implementing a two-stage MSWIFT separation strategy, the number of peptide and protein identifications increased. Further experiments are currently underway investigating multi-stage separations using the MSWIFT device to increase the depth of proteome coverage. These proof-of-concept experiments illustrate the utility of MSWIFT as a highthroughput device that provides flexibility, increased sample load capacity, and eliminates the need for sample clean-up for mass spectrometry-based proteomic studies.

\section{Acknowledgments}

The authors acknowledge funding for this work by the U.S. Department of Energy, Division of Chemical Sciences, Basic Energy Sciences (BES DE-FG02-04ER15520), Department of Health and Human Services, National Institutes of Health, National Center for Research Resources (1 S10 RR022378-01), and the Office of Vice President for Research, Texas A and M University.

\section{Appendix A Supplementary Material}

Supplementary material associated with this article may be found in the online version at doi:10.1016/ j.jasms.2010.04.010.

\section{References}

1. Righetti, P. G.; Castagna, A.; Herbert, B.; Reymond, F.; Rossier, J. S. Prefractionation Techniques in Proteome Analysis. Proteomics 2003, 3, 1397-1407.

2. Kolin, A. Separation and Concentration of Proteins in a $\mathrm{pH}$ Field Combined with an Electric Field. J. Chem. Phys. 1954, 22, 1628-1629.

3. Svensson, H. Isoelectric Fractionation, Analysis, and Characterization of Ampholytes in Natural pH Gradients. 1. Differential Equation of Solute Concentrations at a Steady State and Its Solution for Simple Cases. Acta Chem. Scand. 1961, 15, 325-341. 
4. Gygi, S. P.; Corthals, G. L.; Zhang, Y.; Rochon, Y.; Aebersold, R. Evaluation of Two-Dimensional Gel Electrophoresis-Based Proteome Analysis Technology. Proc. Natl. Acad. Sci. U.S.A. 2000, 97, 9390-9395.

5. Jensen, P. K.; Pasa-Tolic, L.; Anderson, G. A.; Horner, J. A.; Lipton, M. S.; Bruce, J. E.; Smith, R. D. Probing Proteomes Using Capillary Isoelectric Focusing-Electrospray Ionization Fourier Transform Ion Cyclotron Resonance Mass Spectrometry. Anal. Chem. 1999, 71, 2076-2084.

6. Heller, M.; Michel, P.; Morier, P.; Crettaz, D.; Wenz, C.; Tissot, J. D.; Reymond, F.; Rossier, J. S. Two Stage Off-Gel Isoelectric Focusing: Protein Followed by Peptide Fractionation and Application to Proteome Analysis of Human Plasma. Electrophoresis 2005, 26, 1174-1188.

7. Righetti, P. G.; Bossi, A.; Wenisch, E.; Orsini, G. Protein Purification in Multicompartment Electrolyzers with Isoelectric Membranes. J. Chromatogr. B 1997, 699, 105-115.

8. Righetti, P. G.; Bossi, A. Isoelectric Focusing of Proteins and Peptides in Gel Slabs and in Capillaries. Anal. Chim. Acta 1998, 372, 1-19.

9. Anderson, L.; Anderson, N. G. High-Resolution 2-Dimensional Electrophoresis of Human-Plasma Proteins. Proc. Natl. Acad. Sci. U.S.A. 1977, $74,5421-5425$

10. Anderson, N. L.; Anderson, N. G. A Two-Dimensional Gel Database of Human Plasma-Proteins. Electrophoresis 1991, 12, 883-906.

11. Henzel, W. J.; Billeci, T. M.; Stults, J. T.; Wong, S. C.; Grimley, C.; Watanabe, C. Identifying Proteins from Two-Dimensional Gels by Molecular Mass Searching of Peptide-Fragments in Protein-Sequence Databases. Proc. Natl. Acad. Sci. U.S.A. 1993, 90, 5011-5015.

12. Gorg, A.; Weiss, W.; Dunn, M. J. Current Two-Dimensional Electrophoresis Technology for Proteomics. Proteomics 2004, 4, 3665-3685.

13. Righetti, P. G.; Barzaghi, B.; Luzzana, M.; Manfredi, G.; Faupel, M. A Horizontal Apparatus for Isoelectric Protein-Purification in a Segmented Immobilized pH Gradient. J. Biochem. Biophys. Methods 1987, 15, 189-198.

14. Zuo, X.; Speicher, D. W. A Method for Global Analysis of Complex Proteomes Using Sample Prefractionation by Solution Isoelectrofocusing Prior to Two-Dimensional Electrophoresis. Anal. Biochem. 2000, 284, 266-278.

15. Ros, A.; Faupel, M.; Mees, H.; van Oostrum, J.; Ferrigno, R.; Reymond, F.; Michel, P.; Rossier, J. S.; Girault, H. H. Protein Purification by Off-Gel Electrophoresis. Proteomics 2002, 2, 151-156.

16. Ramachandran, P.; Boontheung, P.; Xie, Y. M.; Sondej, M.; Wong, D. T.; Loo, J. A. Identification of N-Linked Glycoproteins in Human Saliva by Glycoprotein Capture and Mass Spectrometry. J. Proteome Res. 2006, 5, 1493-1503.

17. Han, M. J.; Herlyn, M.; Fisher, A. B.; Speicher, D. W. Microscale Solution Ief Combined with 2-D Dige Substantially Enhances Analysis Depth of Complex Proteomes Such As Mammalian Cell and Tissue Extracts. Electrophoresis 2008, 29, 695-705.

18. Myung, J.-K.; Lubec, G. Use of Solution-Ief-Fractionation Leads to Separation of 2673 Mouse Brain Proteins Including 255 Hydrophobic Structures. J. Proteome Res. 2008, 5, 1267-1275.

19. Michel, P. E.; Crettaz, D.; Morier, P.; Heller, M.; Gallot, D.; Tissot, J. D.; Reymond, F.; Rossier, J. S. Proteome Analysis of Human Plasma and Amniotic Fluid by Off-Gel (Tm) Isoelectric Focusing Followed by Nano-LC-MS/MS. Electrophoresis 2006, 27, 1169-1181.

20. Herbert, B.; Righetti, P. G. A Turning Point in Proteome Analysis: Sample Prefractionation Via Multicompartment Electrolyzers with Isoelectric Membranes. Electrophoresis 2000, 21, 3639-3648.

21. Martin, A. J. P.; Hampson, F. New Apparatus for Isoelectric-Focusing. J. Chromatogr. 1978, 159, 101-110.

22. Ogle, D.; Ho, A.; Gibson, T.; Rylatt, D.; Shave, E.; Lim, P.; Vigh, G. Preparative-Scale Isoelectric Trapping Separations Using a Modified Gradiflow Unit. J. Chromatogr. A 2002, 979, 155-161.

23. EsteveRomero, J. S.; Bossi, A.; Righetti, P. G. Purification of Thermamylase in Multicompartment Electrolyzers with Isoelectric Membranes: The Problem of Protein Solubility. Electrophoresis 1996, 17, 1242-1247.

24. Shave, E.; Vigh, G. Preparative-Scale, Recirculating, pH-Biased Binary Isoelectric Trapping Separations. Electrophoresis 2004, 25, 381-387.

25. Lim, P.; North, R.; Vigh, G. Rapid Isoelectric Trapping in a Micropreparative-Scale Multicompartment Electrolyzer. Electrophoresis 2007, $28,1851-1859$
26. Waller, L. N.; Shores, K.; Knapp, D. R. Shotgun Proteomic Analysis of Cerebrospinal Fluid Using Off-Gel Electrophoresis as the FirstDimension Separation. J. Proteome Res. 2008, 7, 4577-4584.

27. Manadas, B.; English, J. A.; Wynne, K. J.; Cotter, D. R.; Dunn, M. J Comparative Analysis of Off-Gel, Strong Cation Exchange with $\mathrm{pH}$ Gradient, and $\mathrm{Rp}$ at High $\mathrm{pH}$ for First-Dimensional Separation of Peptides from a Membrane-Enriched Protein Fraction. Proteomics 2009, 9, 5194-5198.

28. Hubner, N. C.; Ren, S.; Mann, M. Peptide Separation with Immobilized Pi Strips Is an Attractive Alternative to in-Gel Protein Digestion for Proteome Analysis. Proteomics 2008, 8, 4862-4872.

29. de Godoy, L. M. F.; Olsen, J. V.; Cox, J.; Nielsen, M. L.; Hubner, N. C.; Frohlich, F.; Walther, T. C.; Mann, M. Comprehensive Mass-SpectrometryBased Proteome Quantification of Haploid Versus Diploid Yeast. Nature 2008, 455, 1251-1260.

30. Lengqvist, J.; Uhlen, K.; Lehtio, J. iTRAQ Compatibility of Peptide Immobilized $\mathrm{pH}$ Gradient Isoelectric Focusing. Proteomics 2007, 7, 1746-1752.

31. Chenau, J.; Michelland, S.; Sidibe, J.; Seve, M. Peptides Off-Gel Electrophoresis: A Suitable Preanalytical Step for Complex Eukaryotic Samples Fractionation Compatible with Quantitative iTRAQ Labeling. Proteome Sci. 2008, 6, 9 .

32. Lim, P. Dissertation, Texas A and M University, College Station, 2006.

33. Lalwani, S.; Shave, E.; Vigh, G. High-Buffering Capacity Hydrolytically Stable, Low-Pl Isoelectric Membranes for Isoelectric Trapping Separations. Electrophoresis 2004, 25, 3323-3330.

34. Lalwani, S.; Shave, E.; Fleisher, H. C.; Nzeadibe, K.; Busby, M. B.; Vigh, G. Alkali-Stable High-Pl Isoelectric Membranes for Isoelectric Trapping Separations. Electrophoresis 2004, 25, 2128-2138.

35. Fleisher, H. C.; Vigh, G. Hydrolytically Stable, Diaminocarboxylic Acid-Based Membranes Buffering in the pH Range from 6 to 8.5 for Isoelectric Trapping Separations. Electrophoresis 2005, 26, 2511-2519.

36. Fleisher-Craver, H. C.; Vigh, G. PVA-Based Tunable Buffering Membranes for Isoelectric Trapping Separations. Electrophoresis 2008, 29, 4247-4256.

37. Gasteiger, E.; Gattiker, A.; Hoogland, C.; Ivanyi, I.; Appel, R. D.; Bairoch, A. ExPASy: The Proteomics Server for In-Depth Protein Knowledge and Analysis. Nucleic Acids Res. 2003, 31, 3784-3788.

38. Bradford, M. M. Rapid and Sensitive Method for Quantitation of Microgram Quantities of Protein Utilizing Principle of Protein-Dye Binding. Anal. Biochem. 1976, 72, 248-254.

39. Rosas-Acosta, G.; Russell, W. K.; Deyrieux, A.; Russell, D. H.; Wilson, V. G. A Universal Strategy for Proteomic Studies of Sumo and Other Ubiquitin-Like Modifiers. Mol. Cell. Proteom. 2005, 4, 56-72.

40. Perkins, D. N.; Pappin, D. J. C.; Creasy, D. M.; Cottrell, J. S. ProbabilityBased Protein Identification by Searching Sequence Databases Using Mass Spectrometry Data. Electrophoresis 1999, 20, 3551-3567.

41. Knochenmuss, R.; Stortelder, A.; Breuker, K.; Zenobi, R. Secondary Ion-Molecule Reactions in Matrix-Assisted Laser Desorption/Ionization. J. Mass Spectrom. 2000, 35, 1237-1245.

42. Cargile, B. J.; Stephenson, J. L. An Alternative to Tandem Mass Spectrometry: Isoelectric Point and Accurate Mass for the Identification of Peptides. Anal. Chem. 2004, 76, 267-275.

43. Washburn, M. P.; Wolters, D.; Yates, J. R. Large-Scale Analysis of the Yeast Proteome by Multidimensional Protein Identification Technology. Nat. Biotechnol. 2001, 19, 242-247.

44. Breci, L.; Hattrup, E.; Keeler, M.; Letarte, J.; Johnson, R.; Haynes, P. A Comprehensive Proteomics in Yeast Using Chromatographic Fractionation, Gas Phase Fractionation, Protein Gel Electrophoresis, and Isoelectric Focusing. Proteomics 2005, 5, 2018-2028.

45. Cargile, B. J.; Talley, D. L.; Stephenson, J. L. Immobilized pH Gradients as a First Dimension in Shotgun Proteomics and Analysis of the Accuracy of Pi Predictability of Peptides. Electrophoresis 2004, 25 936-945.

46. Cargile, B. J.; Sevinsky, J. R.; Essader, A. S.; Stephenson, J. L.; Bundy, J. L. Immobilized pH Gradient Isoelectric Focusing as a First-Dimension Separation in Shotgun Proteomics. J. Biomol. Techniques 2005, 16, 181189. 